\title{
Secondary sclerosing cholangitis following cardiac surgery: An uncommon but deadly gastrointestinal complication
}

\author{
Kevin Landolfo, MD, and Erol Belli, MD
}

\author{
From the Department of Cardiothoracic Surgery, Mayo Clinic Florida, Jacksonville, Fla. \\ Disclosures: Authors have nothing to disclose with regard to commercial support. \\ Received for publication May 9, 2017; accepted for publication May 11, 2017; available ahead of print June 16, \\ 2017. \\ Address for reprints: Kevin Landolfo, MD, 4500 San Pablo Blvd, Jacksonville, FL 32224 (E-mail: landolfo. \\ kevin@mayo.edu) \\ J Thorac Cardiovasc Surg 2017;154:913-4 \\ $0022-5223 / \$ 36.00$ \\ Copyright (C 2017 by The American Association for Thoracic Surgery \\ http://dx.doi.org/10.1016/j.jtcvs.2017.05.019
}

Gastrointestinal complications following cardiac surgery carry a mortality rate of $>30 \%{ }^{1,2}$ Secondary sclerosing cholangitis in a critically ill patient (SC-CIP) is a rare cholangiopathy associated with a grim prognosis that may go unrecognized in patients undergoing cardiac surgery. SC-CIP is a cholestatic process leading to biliary obstruction, with ischemia and biliary destruction as the central pathological features. ${ }^{3}$ The diagnosis of SC-CIP requires endoscopic retrograde cholangiopancreatography (ERCP), and liver transplantation is the sole curative treatment option. ${ }^{4}$ Contemporary critical care management and the increased use of mechanical circulatory support allows long-term survival of patients with postcardiotomy shock; however, failure to recognize postsurgical complications such as SC-CIP, with high mortality and limited treatment options, may prolong futile resuscitation efforts. ${ }^{1-7}$

In this issue of the Journal, Schade and colleagues present a single institution experience of 12 patients who developed SC-CIP following cardiac surgery with the aim of to increasing the awareness of this rare and often fatal complication. $^{8}$ None of the patients had evidence of preexisting liver dysfunction. The diagnosis of SC-CIP was often delayed, underscoring the difficulty in recognizing this complication. Although elevated liver enzyme values are commonly seen in patients in the intensive care unit (ICU; 30\%), the incidence of SC-CIP following cardiac surgery, also preceded by liver enzyme elevations, was low (0.14\%). However, the mortality rate in the patients with SC-CIP was sobering, with only a single survivor. All of the patients with SC-CIP had postcardiotomy shock, necessitating prolonged and complicated ICU admission. Notably, 50\% of the patients with SC-CIP required mechanical circulatory support with extracorporeal membrane oxygenation or postoperative intra-aortic balloon pump insertion.

Based on their comparative analysis (cases matched 3:1 with controls with similar demographic variables and cardiac procedures), the authors identified several distinct clinical features in the patients with SC-CIP. In addition mechanical circulatory support, these patients required prolonged mechanical ventilation and inotropic administration

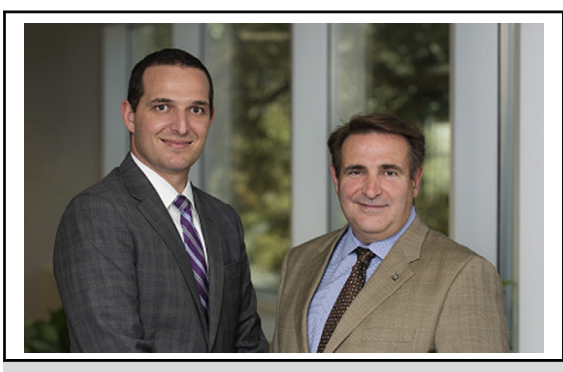

Erol Belli, MD, and Kevin Landolfo, MD

Central Message

Secondary sclerosing cholangitis after cardiac surgery is rare entity with poor survival. Endoscopic drainage of the bile ducts is palliative, but liver transplantation remains the sole therapeutic option.

See Article page 906.

(norepinephrine in particular). Reexploration was performed in $>80 \%$ of the patients. Common indications for reoperation included hemorrhage, wound healing complications, and mediastinitis (median, 3 repeat procedures per patient). Liver enzymes (alkaline phosphatase, gamma-glutamyl transferase, and bilirubin) rose to higher levels in the patients with SC-CIP compared with matched controls; however, despite these marked liver enzyme abnormalities, the diagnosis of SC-CIP was commonly delayed. In most patients, confirmatory ERCP was performed more than 3 weeks after surgery (median, 25 days). ERCP-directed diagnosis and drainage was palliative, with curative treatment in the sole survivor achieved by liver transplantation. The prognosis in patients with SC-CIP was grim, with an overall mortality in this series of $92 \%$. Death was most frequently related to multi-organ system failure after a mean ICU admission of 45 days.

This report adds another condition to the list of lethal gastrointestinal complications that can occur after cardiac surgery. Increased awareness of SC-CIP by cardiothoracic surgeons and intensivists should allow for earlier diagnosis. Palliation is the goal in most cases, with definitive liver transplantation limited to highly selected patients with SC-CIP.

\section{References}

1. Andersson B, Nilsson J, Brandt J, Hoglund P, Andersson R. Gastrointestinal complications after cardiac surgery. Br J Surg. 2005;92:326-33. 
2. Mangi AA, Christison-Lagay ER, Torchiana DF, Warshaw AL, Berger DL. Gastrointestinal complications in patients undergoing heart operation: an analysis of 8709 consecutive cardiac surgical patients. Ann Surg. 2005;241: 895-901.

3. Esposito I, Kubisova A, Stiehl A, Kulaksiz H, Schirmacher P. Secondary sclerosing cholangitis after intensive care unit treatment: clues to the histopathological differential diagnosis. Virchows Arch. 2008;453:339-45.

4. Voigtlander T, Jaeckel E, Lehner F, Manns MP, Lankisch TO. Liver transplantation for critically Ill patients with secondary sclerosing cholangitis: outcome and complications. Liver Transpl. 2015;21:1295-9.
5. Al-Benna S, Willert J, Steinau HU, Steinstraesser L. Secondary sclerosing cholangitis following major burn injury. Burns. 2010;36:e106-10.

6. Gelbmann CM, Rummele P, Wimmer M, Hofstädter F, Göhlmann B, Endlicher E, et al. Ischemic-like cholangiopathy with secondary sclerosing cholangitis in critically ill patients. Am J Gastroenterol. 2007;102:1221-9.

7. Gossard AA, Angulo P, Lindor KD. Secondary sclerosing cholangitis: a comparison to primary sclerosing cholangitis. Am J Gastroenterol. 2005;100:1330-3.

8. Schade I, Radakovic D, Hoffmann J, Sommer S-P, Stefenelli U, Schimmer C, et al. Secondary sclerosing cholangitis in cardiac surgical patients: a complication with a dismal prognosis. J Thorac Cardiovasc Surg. 2017;154:906-12. 